\title{
A Multiobjective Fuzzy Aggregate Production Planning Model Considering Real Capacity and Quality of Products
}

\author{
Najmeh Madadi and Kuan Yew Wong \\ Department of Manufacturing and Industrial Engineering, Faculty of Mechanical Engineering, Universiti Teknologi Malaysia, \\ Skudai, Malaysia
}

Correspondence should be addressed to Kuan Yew Wong; wongky@fkm.utm.my

Received 3 April 2014; Revised 29 July 2014; Accepted 31 July 2014; Published 11 September 2014

Academic Editor: Michael Freitag

Copyright (c) 2014 N. Madadi and K. Y. Wong. This is an open access article distributed under the Creative Commons Attribution License, which permits unrestricted use, distribution, and reproduction in any medium, provided the original work is properly cited.

\begin{abstract}
In this study, an attempt has been made to develop a multiobjective fuzzy aggregate production planning (APP) model that best serves those companies whose aim is to have the best utilization of their resources in an uncertain environment while trying to keep an acceptable degree of quality and customer service level simultaneously. In addition, the study takes into account the performance and availability of production lines. To provide the optimal solution to the proposed model, first it was converted to an equivalent crisp multiobjective model and then goal programming was applied to the converted model. At the final step, the IBM ILOG CPLEX Optimization Studio software was used to obtain the final result based on the data collected from an automotive parts manufacturing company. The comparison of results obtained from solving the model with and without considering the performance and availability of production lines, revealed the significant importance of these two factors in developing a real and practical aggregate production plan.
\end{abstract}

\section{Introduction}

Since the introduction of aggregate production planning (APP) problem in 1950s, it has been studied vastly by many researchers. The interest in APP has a root in the ability that it provides to companies for effective control of production and inventory costs as the two substantial portions of the overall cost of manufacturers [1]. It also helps to identify decisions concerning layoff and hiring of workers, overtime production quantities, backorder and inventory levels, subcontracting, and all the required resources $[2,3]$.

The overall goal of APP is to set the overall production rates for each product category to meet the fluctuation of customers' demand in a cost-effective manner and for a certain time horizon [4]. While APP is considered as an upper level planning in the process of production management, other forms of disaggregation plans (e.g., master production schedule, capacity plan, and material requirements plan) are all related and dependent on APP in a hierarchical way [5]. The costs associated with APP mostly consist of costs related to payroll, inventory, backordering, hiring and layoff of workers, overtime, and regular time production [6]. The time horizon for developing an APP is often from 3 to 18 months forward [7].

Taking into account the beneficial impact of applying APP in companies, different approaches and methodologies such as linear programming $[8,9]$, mixed integer linear programming [6, 10-13], goal programming [14-17], or, in the case of providing solutions to the developed mathematical models, some heuristic algorithms such as genetic algorithm $[7,18,19]$ and tabu search $[17,20-22]$ have been applied. In most of the previously performed studies, APP has been introduced as the method by which decision makers trade off between incurring cost and increasing capacity, having inventory or backlog orders. Although, a successful combination of such trade-offs can bring beneficial results to the company, there may be some other influential factors that should be taken into account when developing an APP. For instance, the quality of products has not received adequate attention in previous studies in the area of APP. Ignoring the quality of products and just focusing on minimizing operational cost in the process of production planning lead to poor customers' 
perception about the products and consequently sales loss in the long term.

The other issue in developing an aggregate production plan is the uncertain environment that the planner has to deal with. The uncertainty in production planning process is due to imprecise input data such as the size and amount of required or on-hand resources, customers' demand, or uncertainty about the aspiration levels of a decision maker's goals and objectives [23]. Therefore, suitable approaches should be followed to incorporate these uncertainties when developing an APP. Fuzzy programming is one of the main approaches used vastly in the literature to incorporate uncertainty into production plans [24]. This study also applies the fuzzy programming approach to consider the aforementioned uncertainties in developing the APP. In addition, because of the lack of attention given to the quality of products in previous related research, this study incorporates quality as an objective function in developing the APP.

The other contribution of this paper is the capability of the developed APP model in considering the real capacity of production lines through incorporating their availability and performance percentage into the capacity constraint of the mathematical model. Considering performance and availability levels of production lines, which takes into account their down time and speed loss, provides the planner with a realistic view of on-hand capacity and consequently results in a more practical APP.

This paper contains eight sections. The next section provides some information about fuzzy programming together with a brief review on some relevant previous studies. Section 3 provides information about the construction of the mathematical model. In Section 4, the approach applied for providing the solution to the model is discussed. Section 5 confirms the applicability of the proposed model using data collected from the company under study. In Section 6, a comparison will be made in order to signify the consequences of ignoring the performance and availability of production lines in developing a practical APP. Sensitivity analysis and conclusions will be presented in Sections 7 and 8, respectively.

\section{Literature Review}

Application of fuzzy set theory in the conventional linear programming model was first introduced by Zimmermann $[25,26]$ in 1978 . The purpose was to deal with the uncertainties in the input data which are mostly due to the lack of decision makers' knowledge and unavailability of required data. Due to the nonrandomness nature of such uncertainties, they cannot be expressed by probability distributions and considering conventional stochastic programming models leads to inefficient and impractical results. On the other hand, assuming the uncertain parameters to be deterministic can also lead to unreal and impractical results [27].

In the fuzzy model proposed by Zimmermann [25] both the objective function and constraints were formulated in a fuzzy environment where imprecise parameters are processed as fuzzy numbers and imprecise constraints as fuzzy sets. Using the min-operator, he showed that there is an equivalent linear programming model to the original constructed fuzzy multiobjective model.

Narasimhan [28] demonstrated how fuzzy subset concept can be incorporated into a goal programming model in a fuzzy environment. Hannan [29] illustrated the application of piecewise membership functions in quantifying fuzzy aspiration levels. He considered a fuzzy goal-programming model with preemptive priorities and Archimedean weights and solved the model by maximization of the membership function of the minimum goal.

Introduction of fuzzy set theory into linear programming models by Zimmermann [26] has opened new windows for researchers who are dealing with a fuzzy environment in different areas of operations management. Based on a survey conducted by Wong and Lai [30], between the years 1998 and 2009, the number of applications of fuzzy set theory in different areas of operations and production management was about 400. Among them, the area of long term capacity planning had the highest share of application, namely, $16.13 \%$, followed by short term capacity planning $(14.4 \%)$ and inventory control (11.17\%). However, the least number of applications was found in the areas of job design and long term forecasting with almost no application. In the area of APP, fuzzy set theory has its own significant place [5, 28, 31-33]. Jamalnia and Soukhakian [23] developed a fuzzy multiobjective nonlinear APP model to address the fuzzy aspiration levels of objective functions. In their model, three quantitative objective functions, namely, minimization of production, inventory, and changes in workers costs, and one qualitative objective function of maximizing customer satisfaction were taken into account. The nonlinearity of the model was due to the effect of the learning curve in decreasing production time as workers achieve more experience. By applying the triangular fuzzy membership function, the model was converted to a crisp one and finally it was solved using a branch of genetic algorithm.

Wang and Fang [34] developed an aggregate production plan with some fuzzy parameters including product price, unit cost of subcontracting, workforce level, production capacity, and market demand along with fuzzy aspiration levels of objective functions. Providing a systematic framework, the proposed approach supports decision makers through an interactive way until the satisfactory results are obtained. At the final step, an aggregation operator was employed in order to obtain the compromised solution of the proposed system.

Wang and Liang [35] also proposed a fuzzy linear programming model and developed an APP. Minimization of total production costs, carrying and backordering costs, and rates of changes in labor levels are the three objective functions of that study. In order to convert the problem into an ordinary linear programming problem, the piecewise linear membership function of Hannan [29] (to represent the fuzzy goals of decision makers) along with the fuzzy decision making approach of Zadeh [36] were taken into account.

The review of several studies in the APP area described in this section obviously shows that almost all researchers have considered cost as the first objective to be minimized. Minimization of inventory, backorder level, and changes in workforce are the other main objectives that have been taken 
into consideration as the second or third objective function. However, enhancing the quality of products as an objective function has been widely ignored in developing APP models. Particularly, there is no study that has taken into account the quality of products when developing an APP in the fuzzy environment. Another deficiency in this area was the overestimation of the real capacity of production lines due to the ignorance of two important factors, that are, performance and availability of production lines in the capacity constraints of the constructed APP models. In this study, an effort has been made to bridge these gaps through developing a multiobjective integer linear programming model in a fuzzy environment in which the quality of products as well as the real capacity of production lines have been taken into consideration. Since, in the real world, planners are faced with qualitative as well as quantitative goals, this study tries to present the application of both qualitative and quantitative objective functions in the construction of the proposed APP model. To test the applicability of the proposed model, it has been applied to a case study chosen from Iran's automotive industry.

\section{Construction of the Mathematical Model}

In this section a multiperiod, multiobjective integer fuzzy linear programming model is constructed based on the operational conditions of an automotive parts manufacturing company in Iran which is producing three types of products for local customers.

3.1. Operational Conditions and Assumptions of the Model. The operational conditions together with the assumptions of the model are as follows.

(i) Forecasted customers' demand, production cost, inventory carrying cost, cost of training, cost of purchasing raw materials, reject rate of raw materials, and performance and availability percentages of all production lines are assumed to be imprecise and are modeled by fuzzy numbers.

(ii) Production lines are balanced.

(iii) Constant number of operators and workers has been dedicated to each production line throughout the specified time horizon.

(iv) The cost of hiring is not included in the overall production cost, since all the operators and workers are hired at the beginning of the time horizon.

(v) Firing the hired workers is not allowable. Workers are trained to acquire the required level of skills in each time period.

(vi) Regular and overtime production and warehouse space cannot exceed their maximum levels.

(vii) Backordered demand must be satisfied in the next time period.

(viii) All customers' demand for all types of products should be fulfilled at the end of the time horizon. (ix) Outsourcing is not allowable for any type of products.

(x) The number of workers with a certain skill level in a time period is not reduced in the next time period.

(xi) Work in process (WIP) inventory cost is not considered.

(xii) The specified time horizon contains six monthly periods.

(xiii) Two separated warehouses are used for final products storage; one is assigned to the type one and type two products and the other warehouse is for storing products of type three.

(xiv) The level of inventory is assumed to be zero at the beginning of the first period.

(xv) Each type of products is assigned to just one production line.

(xvi) All components can be purchased from all suppliers. In total, three suppliers are considered.

(xvii) Reject rates and costs of raw materials, purchased from different suppliers, are different.

(xviii) Rejected raw materials are sent back to the relevant suppliers and the company does not pay for them.

(xix) Higher skilled workers are paid more.

(xx) The salary of workers is not included in the overall production cost and is considered separately.

\subsection{Objective Functions}

3.2.1. Quantitative Objective Function. Quantitative objective functions are as follows:

(i) minimization of total cost,

(ii) maximization of product quality (through minimization of quality degradation).

3.2.2. Qualitative Objective Function. Customer service level should be "rather high."

The desired service level, that is, "rather high," in the above objective has been identified by the decision maker (production planner in the company under study).

\subsection{Parameters Definition. Consider the following:}

$T=$ planning time horizon including six monthly periods;

$t=$ time period;

$m=$ type of product $(m \in M)$;

$k=$ supplier index $(k \in K)$;

$i=$ raw material component $(i \in I)$;

$n_{\text {im }}=$ usage coefficient of component $i$ in product $m$;

$h=$ regular $(h=1)$ or overtime $(h=2)$ production hours $(h \in H)$;

sk $=$ skill level of a worker (ordinary $(\mathrm{sk}=1)$, good $(\mathrm{sk}=2)$, and excellent $(\mathrm{sk}=3))$; 
$S_{\text {sk }}=$ salary of a worker with skill level of sk;

$\widetilde{C}_{i k}=$ cost of component $i$ purchased from supplier $k$ (cost of placing and receiving orders);

$\tilde{\theta}_{i k}=$ reject rate of component $i$ purchased from supplier $k$;

$\widetilde{D}_{m t}=$ forecasted demand of product type $m$ in period $t$

$\tau_{m}=$ ideal production cycle time for product type $m$;

$\widetilde{C}_{m h}^{p}=$ cost of producing one unit of product type $m$ in production time $h$;

$\widetilde{C}_{m t}^{I}=$ inventory carrying cost per unit of product $m$ in period $t$;

$C_{m}^{B}=$ backorder cost per unit of product $m$;

$\widetilde{C}_{h t}=$ cost to train one worker in period $t$;

$\widetilde{\operatorname{Pr}}_{m}=$ performance percentage of production line $m$;

$\widetilde{A v}_{m}=$ availability percentage of production line $m$;

$L_{m t}^{W}=$ number of workers to be assigned for producing product type $m$ in period $t$;

$\operatorname{Max}^{w m 1}=$ maximum warehouse space for storage of product types 1 and 2;

$\operatorname{Max}^{w m 2}=$ maximum warehouse space for storage of product type 3;

$\operatorname{Max}^{h t}=$ maximum allowable regular time $(h=1)$ or overtime $(h=2)$ production in period $t$;

$W_{m}=$ required warehouse space per unit of product $m$.

All input data related to the parameters will be made available upon request.

3.4. Decision Variables. Decision variables (outputs of the model) are as follows:

$P_{m h t}=$ unit of product type $m$ to be produced in production time $h$ (regular time or overtime) in period $t$;

$L_{m t}^{h}=$ number of workers to be trained in period $t$ for product type $m$;

$B_{m t}=$ backorder level at the end of period $t$ for product type $m$;

$I_{m t}=$ available inventory level of product type $m$ at the end of period $t$;

$Q_{i k t}=$ quantity of component $i$ to be purchased from supplier $k$ in period $t$;

$L_{\mathrm{sk} m t}=$ number of workers with skill level of sk to produce product type $m$ in period $t$.

3.5. Formulation of Objective Functions. The objective functions are formulated as follows.

\subsubsection{Quantitative Objective Functions}

(i) Minimization of cost is as follows:

$\operatorname{Min} Z_{1}$

$$
\begin{aligned}
= & \sum_{t=1}^{T} \sum_{m=1}^{M} \sum_{h=1}^{H} \widetilde{C}_{m h}^{p} P_{m h t}+\sum_{t=1}^{T} \sum_{m=1}^{M}\left(C_{m}^{B} B_{m t}+\widetilde{C}_{m t}^{I} I_{m t}+\widetilde{C}_{h t} L_{m t}^{h}\right) \\
& +\sum_{t=1}^{T} \sum_{m=1}^{M} \sum_{\mathrm{sk}=1}^{3} S_{\mathrm{sk}} L_{\mathrm{sk} m t}+\sum_{t=1}^{T} \sum_{k=1}^{K} \sum_{i=1}^{I} \widetilde{C}_{i k} Q_{i k t} .
\end{aligned}
$$

This objective function tries to minimize operational costs including production cost, backorder cost, inventory cost, training cost, and costs associated with salary and raw materials procurement.

(ii) Maximization of quality of products (minimization of quality degradation) is as follows:

$\operatorname{Min} Z_{2}=\frac{\sum_{i=1}^{I} \sum_{k=1}^{K} \sum_{t=1}^{T} Q_{i k t} \widetilde{\theta}_{i k}}{\sum_{i=1}^{I} \sum_{m=1}^{M} \sum_{t=1}^{T} \widetilde{D}_{m t} n_{i m}}+\frac{\sum_{m=1}^{M} \sum_{\mathrm{sk}=1}^{1} \sum_{t=1}^{T} L_{\mathrm{sk} m t}}{\sum_{m=1}^{M} \sum_{t=1}^{T} L_{m t}^{W}}$.

The aim of this objective function is to maximize quality by minimizing quality degradation of products using two strategies. The first strategy, as has been formulated in the first element, is to decrease the number of rejected raw materials purchased from suppliers and the second strategy represented in the second element of the objective function is to decrease the number of hired workers with a lower skill level. These two elements have a significant effect on the quality of finished products produced during the specified time horizon. One can add other elements that are effective on the quality of finished products, depending on the situation of the company under study.

\subsubsection{Qualitative Objective Functions}

(i) "Customer service level should be rather high."

In order to measure customer service level, backorder level is used. The term "rather high" has been defined by the decision maker as the desired service level that the company aims to provide to its customers. Figure 1 shows the corresponding membership functions [27] constructed based on the definition of the decision maker and assigned to each linguistic term in Set $A$, where $A=$ \{very low, low, rather low, medium, rather high, high, very high\}.

To formulate the required linguistic term, the part that has been assigned to "rather high ( $\mathrm{RH})$ " and highlighted in Figure 1 has been selected and formulated as shown in

$$
\mu_{\mathrm{BLP}_{t}}= \begin{cases}1 & \mathrm{BLP}_{t} \leq 25 \\ \frac{30-\mathrm{BLP}_{t}}{5} & 25<\mathrm{BLP}_{t} \leq 30 \\ 0 & \mathrm{BLP}_{t}>30\end{cases}
$$




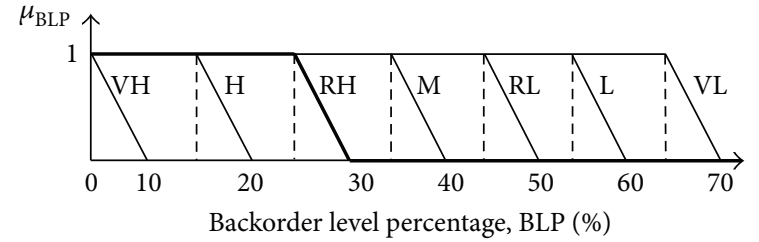

Figure 1: Membership functions for different linguistic terms.

where

$\mathrm{BLP}_{t}$ (Backorder level percentage at the end of period $t$ )

$$
=\frac{\text { Backorder at the end of period } t}{\text { Demand in period } t} \times 100 \text {. }
$$

Therefore the final formula for the third objective function can be constructed as presented in

$$
\operatorname{Max} Z_{3}=\sum_{t=1}^{T} \mu_{\mathrm{BLP}_{t}}=\sum_{t=1}^{T} \frac{30-\mathrm{BLP}_{t}}{5}
$$

3.6. Constraints. The following constraints have been formulated based on the assumptions and the company's operational conditions defined earlier:

$$
\begin{aligned}
& \sum_{h=1}^{2} P_{m h t}=\widetilde{D}_{m t}-I_{m(t-1)}-B_{m t}+I_{m t}+B_{m(t-1)} \\
& \forall t>1, \quad \forall m \\
& \sum_{h=1}^{2} P_{m h t}=\widetilde{D}_{m t}-B_{m t}+I_{m t} ; \quad \forall m, t=1 \\
& \sum_{\mathrm{sk}=1}^{3}\left(L_{\mathrm{sk} m t}-L_{\mathrm{sk} m(t-1)}\right)=L_{m t}^{h} ; \quad \forall t>1, \forall m \\
& L_{\mathrm{sk} m t} \geq L_{\mathrm{sk} m(t-1)} ; \quad \forall t>1, \forall m, \forall \mathrm{sk} \\
& \sum_{\mathrm{sk}=1}^{3} L_{\mathrm{sk} m t}=L_{m t}^{W} ; \quad \forall m, \quad \forall t \\
& P_{m h t} \tau_{m} \leq \operatorname{Max}^{h t} \times \underbrace{\widetilde{\operatorname{Pr}}_{m} \times \widetilde{\mathrm{Av}}_{m}}_{\widetilde{\mathrm{PA}}_{m}} ; \quad \forall m, \quad \forall t, \quad \forall h \\
& B_{m t} \leq \widetilde{D}_{m t} ; \quad \forall t, \forall m \\
& B_{m t}=0 ; \quad \forall m, \forall t=6 \\
& \sum_{m=1}^{2} W_{m} I_{m t} \leq \operatorname{Max}^{w m 1} ; \quad \forall t \\
& W_{m} I_{m t} \leq \operatorname{Max}^{w m 2} ; \quad \forall t, \quad \forall m=3 \\
& \sum_{k=1}^{3} Q_{i k t}=\sum_{m=1}^{3} \sum_{h=1}^{2}\left(P_{m h t} \times n_{i m}\right) ; \quad \forall t, \forall i .
\end{aligned}
$$

Constraints (6) and (7) determine the production quantities in regular and overtime production hours. Constraint (8) defines the number of workers to be trained in each time period. Constraint (9) is generated based on the company's layoff strategy that forbids firing the hired workers and hiring higher skill workers. Due to the company's training strategy, workers are trained to achieve the required skills. Therefore, as formulated in constraint (9), the number of workers with higher skills in a time period should increase or remain constant compared to the former time period. Constraint (10) ensures that the total number of workers with different skill levels for producing a certain type of product is equal to the number of dedicated workers to the corresponding production line. Constraint (11) considers the limitation associated with the capacity of production lines taking into account performance and availability percentages of production lines. To be more illustrative, the formulas used for obtaining the values of performance and availability percentages of production lines are presented as follows:

Availability percentage of production line $m\left(\mathrm{Av}_{m}\right)$

$$
=\left(\frac{\text { Operating time }}{\text { Planned production time }}\right) \times 100 \text {, }
$$

in which operating time is obtained from subtracting shut down durations (such as equipment failure, material shortage, and changeover time) from the planned production time.

Performance percentage of production line $m\left(\operatorname{Pr}_{m}\right)$

$$
=\left(\frac{\text { Net operating time }}{\text { Operating time }}\right) \times 100 \text {, }
$$

where net operating time is the result of removing speed loss durations (such as machine wear, substandard material, and operator inefficiency) from the operating time.

Constraint (12) states that the backorder level must not exceed the customer demand in each time period. Constraint (13) imposes an obstacle on having any backorder level at the end of the specified time horizon. Constraints (14) and (15) emphasize the limits on the warehouses' capacity for storing finished products and finally constraint (16) identifies the quantity of raw materials to be purchased from the suppliers.

\section{Providing a Solution to the Model}

In general, in the process of solving a possibilistic fuzzy programming problem, the uncertain nature of parameters imposes two main issues: managing the relationship between the fuzzy sides of constraints and obtaining the optimal value for the objective function which involves some fuzzy parameters. Based on Jiménez et al. [37] the answers for these two questions are related to the process of ranking fuzzy numbers. Many approaches have been introduced in the literature addressing the problem of ranking fuzzy numbers [38]. This study applies the method introduced by Jiménez et al. [37] to rank the fuzzy constraints and objectives. The method uses two main concepts, that are, feasibility and optimality, for dealing with inequality relations in constraints 
and ranking fuzzy objective functions, respectively. Unlike some ranking approaches that do not agree with each other, this approach verifies all properties used in other ranking approaches applied for ranking fuzzy numbers [37]. In addition, the method preserves the linearity of a linear programming model that makes it computationally efficient. It also does not increase the number of objective functions and inequality constraints [27]. Therefore, it is suitable for solving large scale fuzzy linear programming models. The method uses fuzzy relation for comparison of fuzzy numbers, while many other relevant methods use comparison relation that does not provide any information about likely violation of constraints (feasibility concept) and just simply state that a fuzzy number is bigger or smaller than others [37]. The feasibility and optimality concepts in this method allow the decision maker to interactively make a trade-off between the degree of violation of constraints (feasibility degree) and the degree of accomplishment of her/his targeted goal. This method is based on an expected interval and expected value of fuzzy numbers, which are considered as the two strong mathematical concepts [39] and were initially introduced by Yager [40] and Dubois and Prade [41] and continued by Heilpern [42] and Jiménez et al. [37]. Prior to explaining the methodology used for solving the constructed fuzzy mathematical model, some relevant terms are defined in the following section.

\subsection{Definition of Terms}

Fuzzy Number. A fuzzy number is a fuzzy set $\widetilde{a}$ on the real line $R$ with the membership function shown in

$$
u=\mu_{\tilde{a}}(x)= \begin{cases}0 & \forall x \in\left(-\infty, a_{1}\right] \\ f_{a}(x) & \text { increasing } \forall x \in\left[a_{1}, a_{2}\right] \\ 1 & \forall x \in\left[a_{2}, a_{3}\right] \\ g_{a}(x) & \text { decreasing } \forall x \in\left[a_{3}, a_{4}\right] \\ 0 & \forall x \in\left[a_{4},+\infty\right)\end{cases}
$$

in which $\widetilde{a}=\left(a_{1}, a_{2}, a_{3}, a_{4}\right)$.

An $\alpha$-Cut of a Fuzzy Number $\widetilde{a}$. It is a slice through the fuzzy number $\widetilde{a}$ which produces a nonfuzzy set and is defined as $a_{\alpha}=\left\{x \in R ; \mu_{\tilde{a}}(x) \geq \alpha ; 0<\alpha \leq 1\right\}$. Based on this definition, it can be written as $a_{\alpha}=\left[f_{a}^{-1}(u), g_{a}^{-1}(u)\right]$. In such cases when $f_{a}$ and $g_{a}$ are linear functions, the membership function presented in (19) is the membership function of a trapezoidal fuzzy number, denoted by $\left(a_{1}, a_{2}, a_{3}, a_{4}\right)$. If $a_{2}=a_{3}$, the trapezoidal fuzzy number is converted to the triangular fuzzy number denoted by $\left(a_{1}, a_{2}, a_{3}\right)$ [37].

Expected Interval and Expected Value of a Fuzzy Number. Expected interval of a fuzzy number was first introduced by Heilpern [42]. Considering (19), an expected interval of a triangular fuzzy number can be represented as

$$
\mathrm{EI}(\widetilde{a})=\left[E_{1}^{a}, E_{2}^{a}\right]=\left[\int_{0}^{1} f_{a}^{-1}(u) d u, \int_{0}^{1} g_{a}^{-1}(u) d u\right] .
$$

In addition, based on Heilpern's [42] definition, an expected value of a fuzzy number is half point of its expected interval. Then, we have

$$
\mathrm{EV}(\widetilde{a})=\frac{E_{1}^{a}+E_{2}^{a}}{2} .
$$

Therefore, for a triangular fuzzy number $\tilde{a}=\left(a_{1}, a_{2}, a_{3}\right)$, the resulting interval and expected value would be

$$
\begin{gathered}
\operatorname{EI}(\widetilde{a})=\left[\frac{a_{1}+a_{2}}{2}, \frac{a_{2}+a_{3}}{2}\right], \\
\operatorname{EV}(\widetilde{a})=\frac{a_{1}+2 a_{2}+a_{3}}{4} .
\end{gathered}
$$

It is notable that in some literature, the degree of a decision maker's optimism has been incorporated in calculating the expected interval of a fuzzy number as well.

In addition, based on Dubois and Prade [41], for two fuzzy numbers $\widetilde{a}$ and $\widetilde{b}$, the following equalities are used:

$$
\begin{aligned}
\operatorname{EI}(\rho \tilde{a}+\sigma \widetilde{b}) & =\rho \operatorname{EI}(\widetilde{a})+\sigma \operatorname{EI}(\widetilde{b}), \\
\operatorname{EV}(\rho \widetilde{a}+\sigma \widetilde{b}) & =\rho \operatorname{EV}(\widetilde{a})+\sigma \operatorname{EV}(\widetilde{b}) .
\end{aligned}
$$

Definition 1 (see [43]). For any pair of fuzzy numbers $\widetilde{a}$ and $\widetilde{b}$, the degree in which $\widetilde{a}$ is bigger than $\widetilde{b}$ can be defined as follows:

$$
\begin{aligned}
& \mu_{M}(\tilde{a}, \tilde{b}) \\
& \quad= \begin{cases}0 & \text { if } E_{2}^{a}-E_{1}^{b}<0 \\
\frac{E_{2}^{a}-E_{1}^{b}}{E_{2}^{a}-E_{1}^{b}-\left(E_{1}^{a}-E_{2}^{b}\right)} & \text { if } 0 \in\left[E_{1}^{a}-E_{2}^{b}, E_{2}^{a}-E_{1}^{b}\right] \\
1 & \text { if } E_{1}^{a}-E_{2}^{b}>0,\end{cases}
\end{aligned}
$$

where $\left[E_{1}^{a}, E_{2}^{a}\right]$ and $\left[E_{1}^{b}, E_{2}^{b}\right]$ are the expected intervals of $\widetilde{a}$ and $\widetilde{b}$.

When $\mu_{M}(\widetilde{a}, \widetilde{b})=0.5$, it is said that $\widetilde{a}$ and $\widetilde{b}$ are indifferent, and when $\mu_{M}(\widetilde{a}, \tilde{b}) \geq \alpha$ it is said that $\tilde{a}$ is bigger than, or equal to, $\widetilde{b}$ at least in degree $\alpha$ and we indicate it by $\widetilde{a} \geq_{\alpha} \widetilde{b}$.

Definition 2 (see [43]). Given a decision vector $x \in R^{n}$, it is feasible in degree $\alpha$ (or $\alpha$-feasible) if

$$
\min _{i=1, \ldots, m}\left\{\mu_{M}\left(\widetilde{a}_{i} x, \widetilde{b}_{i}\right)\right\}=\alpha,
$$

where $\widetilde{a}_{i}=\left(\widetilde{a}_{i 1}, \widetilde{a}_{i 2}, \ldots, \widetilde{a}_{i n}\right)$; it can be said that

$$
\widetilde{a}_{i} x \geq_{\alpha} \widetilde{b}_{i}, \quad i=1, \ldots, m .
$$

Referring to (24), it is equivalent to

$$
\frac{E_{2}^{a_{i} x}-E_{1}^{b_{i}}}{E_{2}^{a_{i} x}-E_{1}^{a_{i} x}+E_{2}^{b_{i}}-E_{1}^{b_{i}}} \geq \alpha, \quad i=1, \ldots, m,
$$

or

$$
\left[(1-\alpha) E_{2}^{a_{i}}+\alpha E_{1}^{a_{i}}\right] x \geq \alpha E_{2}^{b_{i}}+(1-\alpha) E_{1}^{b_{i}} .
$$


Definition 2 answers the feasibility issue. In other words, $1-\alpha$ is the risk of unfeasibility of the solution. However, for the optimality issue, we should refer to Definition 3.

Definition 3 (see [43]). Consider the following classical fuzzy linear programming problem with all fuzzy parameters:

$$
\begin{gathered}
\operatorname{Min} \widetilde{c}^{t} x, \\
x \in\left\{x \in R^{n} \mid \widetilde{a}_{i} x \geq \widetilde{b}_{i}, i=1, \ldots, m, x \geq 0\right\},
\end{gathered}
$$

in which $\widetilde{c}=\left(\widetilde{c}_{1}, \widetilde{c}_{2}, \ldots, \widetilde{c}_{n}\right)$ and $\widetilde{a}_{i}=\left(\widetilde{a}_{i 1}, \widetilde{a}_{i 2}, \ldots, \widetilde{a}_{i n}\right)$. All the parameters are described based on triangular fuzzy numbers and decision vector $x \in R^{n}$ is assumed to be crisp. A vector $x_{\alpha}^{*} \in R^{n}$ is an $\alpha$-acceptable optimal solution for model (29), if it is an optimal solution to the following crisp linear programming model:

$$
\begin{gathered}
\operatorname{Min} \operatorname{EV}\left(\widetilde{c}^{t}\right) x \\
x \in\left\{x \in R^{n} \mid \widetilde{a}_{i} x \geq \widetilde{b}_{i}, i=1, \ldots, m, x \geq 0\right\},
\end{gathered}
$$

in which $\widetilde{c}=\left(\widetilde{c}_{1}, \widetilde{c}_{2}, \ldots, \widetilde{c}_{n}\right)$ and $\widetilde{a}_{i}=\left(\widetilde{a}_{i 1}, \widetilde{a}_{i 2}, \ldots, \widetilde{a}_{i n}\right)$.

On the other hand, the set of inequality fuzzy constraints $\tilde{a}_{i} x \geq_{\alpha} \widetilde{b}_{i}, i=1, \ldots, m$, can be converted to their equivalent crisp ones based on Expression (28). Also based on Jiménez et al.s [37] approach, equality constraints of $\tilde{a}_{i} x={ }_{\alpha} \tilde{b}_{i}$ are converted to the following crisp inequalities:

$$
\begin{aligned}
& {\left[\left(1-\frac{\alpha}{2}\right) E_{2}^{a_{i}}+\frac{\alpha}{2} E_{1}^{a_{i}}\right] x \geq \frac{\alpha}{2} E_{2}^{b_{i}}+\left(1-\frac{\alpha}{2}\right) E_{1}^{b_{i}}} \\
& {\left[\left(1-\frac{\alpha}{2}\right) E_{1}^{a_{i}}+\frac{\alpha}{2} E_{2}^{a_{i}}\right] x \leq\left(1-\frac{\alpha}{2}\right) E_{2}^{b_{i}}+\frac{\alpha}{2} E_{1}^{b_{i}} .}
\end{aligned}
$$

4.2. Application of Jiménez et al.s [37] Approach to the Proposed Mathematical Fuzzy Model. As described before, to provide a solution to the model, two main issues of feasibility and optimality of solution must be taken into account. The solution feasibility means to what degree it violates none of the model constraints while the solution optimality implies to what extent the solution achieves the fuzzy goals [44]. In order to answer these main issues, the novel approach of Jiménez et al. [37], with all those details clarified in Section 4.1, are applied to the proposed fuzzy APP model. In brief, the solution to the model will be provided after passing through these phases:

(i) modeling the imprecise data using triangular fuzzy numbers;

(ii) converting the multiobjective fuzzy linear model to an equivalent crisp one;

(iii) solving the resulting multiobjective crisp linear programming model using fuzzy goal programming approach.

4.2.1. Modeling the Imprecise Data Using Triangular Fuzzy Numbers. The first step in solving a fuzzy mathematical model is to represent the uncertain parameters by fuzzy

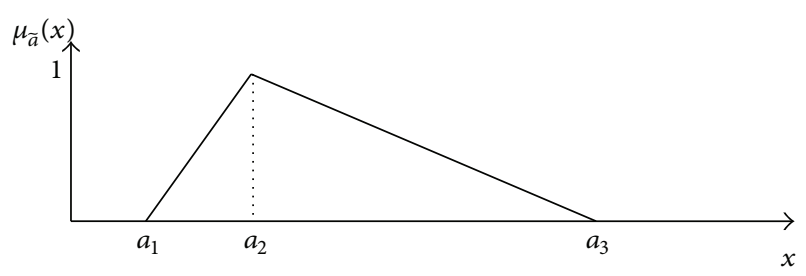

FIgURe 2: Triangular distribution of fuzzy number $\widetilde{a}=\left(a_{1}, a_{2}, a_{3}\right)$.

numbers. The triangular possibilistic distribution is the most common tool to model the imprecise nature of the fuzzy parameters because of its computational efficiency and simplicity in acquisition of data [45]. In this phase, those imprecise data including forecasted demand, production cost, inventory carrying cost, cost of training workers, cost of purchasing raw materials, reject rate of raw materials, and performance and availability percentages of all production lines are modeled by fuzzy numbers. Figure 2 presents a triangular distribution corresponding to a fuzzy number $\tilde{a}=$ $\left(a_{1}, a_{2}, a_{3}\right)$.

The lower bound value $a_{1}$ of fuzzy number $\tilde{a}$ shows the most pessimistic value that has a small likelihood to belong to the set of available values (with a membership value of zero if normalized). The value $a_{2}$ of fuzzy number $\tilde{a}$ shows the most possible value that certainly belongs to the set of available values (with a membership value of 1 after it is normalized). The upper bound value $a_{3}$ as the most optimistic value has a small likelihood to belong to the set of available values (with a membership value of zero if normalized) [46]. Therefore, fuzzy parameters of the proposed model are modeled as follows:

$$
\begin{array}{cc}
\widetilde{D}_{m t}=\left(D_{m t}^{1}, D_{m t}^{2}, D_{m t}^{3}\right) ; & \widetilde{P r}_{m}=\left(\operatorname{Pr}_{m}^{1}, \operatorname{Pr}_{m}^{2}, \operatorname{Pr}_{m}^{3}\right) ; \\
\widetilde{A v}_{m}=\left(\operatorname{Av}_{m}^{1}, \operatorname{Av}_{m}^{2}, \operatorname{Av}_{m}^{3}\right) ; & \widetilde{C}_{i k}=\left(C_{i k}^{1}, C_{i k}^{2}, C_{i k}^{3}\right) ; \\
\widetilde{\theta}_{i k}=\left(\theta_{i k}^{1}, \theta_{i k}^{2}, \theta_{i k}^{3}\right) ; & \widetilde{C}_{h t}=\left(C_{h t}^{1}, C_{h t}^{2}, C_{h t}^{3}\right) ; \\
\widetilde{C}_{m t}^{I}=\left(C_{m t}^{I 1}, C_{m t}^{I 2}, C_{m t}^{I 3}\right) ; & \widetilde{C}_{m h}^{p}=\left(C_{m h}^{p 1}, C_{m h}^{p 2}, C_{m h}^{p 3}\right) ; \\
\widetilde{\mathrm{PA}}_{m}=\widetilde{\operatorname{Pr}}_{m} \times \widetilde{\mathrm{Av}}_{m}=\left(\mathrm{PA}_{m}^{1}, \mathrm{PA}_{m}^{2}, \mathrm{PA}_{m}^{3}\right) .
\end{array}
$$

4.2.2. Converting the Multiobjective Fuzzy Linear Model to an Equivalent Crisp One. Since some of the parameters in the objective functions and constraints are fuzzy numbers, we are faced with both imprecise objectives and imprecise constraints (possibilistic programming). This phase involves the following:

(i) treating imprecise objective functions (optimality issue);

(ii) treating imprecise constraints (feasibility issue).

(a) Treating Imprecise Objective Functions. Since there are some triangular fuzzy parameters in the objective functions, we can express them based on a triangular possibilistic distribution. To obtain $Z_{i}^{1}, Z_{i}^{2}, Z_{i}^{3}$, all fuzzy parameters in the 
objective function $Z_{i}$ are set at their pessimistic, most likely, and optimistic values, respectively. Therefore, the triangular fuzzy numbers for the first objective function (quantitative objective) can be stated as $Z_{1}=\left(Z_{1}^{1}, Z_{1}^{2}, Z_{1}^{3}\right)$, in which

$$
\begin{aligned}
Z_{1}^{1}= & \sum_{t=1}^{T} \sum_{m=1}^{M} \sum_{h=1}^{H} C_{m h}^{p 1} P_{m h t} \\
& +\sum_{t=1}^{T} \sum_{m=1}^{M}\left(C_{m}^{B} B_{m t}+C_{m t}^{I 1} I_{m t}+C_{h t}^{1} L_{m t}^{h}\right) \\
& +\sum_{t=1}^{T} \sum_{m=1}^{M} \sum_{\mathrm{sk}=1}^{3} S_{\mathrm{sk}} L_{\mathrm{sk} m t}+\sum_{t=1}^{T} \sum_{k=1}^{K} \sum_{i=1}^{I} C_{i k}^{1} Q_{i k t} \\
Z_{1}^{2}= & \sum_{t=1}^{T} \sum_{m=1}^{M} \sum_{h=1}^{H} C_{m h}^{p 2} P_{m h t} \\
& +\sum_{t=1}^{T} \sum_{m=1}^{M}\left(C_{m}^{B} B_{m t}+C_{m t}^{I 2} I_{m t}+C_{h t}^{2} L_{m t}^{h}\right) \\
& +\sum_{t=1}^{T} \sum_{m=1}^{M} \sum_{\mathrm{sk}=1}^{3} S_{\mathrm{sk}} L_{\mathrm{sk} m t}+\sum_{t=1}^{T} \sum_{k=1}^{K} \sum_{i=1}^{I} C_{i k}^{2} Q_{i k t} \\
& +\sum_{t=1}^{T} \sum_{m=1}^{M} \sum_{\mathrm{sk}=1}^{H} \sum_{t=1}^{H} C_{m=1}^{p 3} S_{h=1} L_{m h t} \\
& +\sum_{t=1}^{T} \sum_{m=1}^{M}\left(C_{m}^{B} B_{m t}+C_{m t}^{I 3} I_{m t}^{T}+C_{h t}^{3} \sum_{m t}^{K} \sum_{k=1}^{I} C_{i k}^{3} Q_{i k t}\right. \\
Z_{i=1} &
\end{aligned}
$$

The same approach is applied to the second and third objective functions in order to transform them into their equivalent crisp ones. Based on the methodology explained earlier, this phase is continued by introducing expected values of these objective functions as follows:

$$
\begin{aligned}
& \operatorname{EV}_{\gamma}\left(\widetilde{Z}_{1}\right)=(1-\gamma) \frac{Z_{1}^{1}+Z_{1}^{2}}{2}+(\gamma) \frac{Z_{1}^{2}+Z_{1}^{3}}{2} \\
& \operatorname{EV}_{\gamma}\left(\widetilde{Z}_{2}\right)=(1-\gamma) \frac{Z_{2}^{1}+Z_{2}^{2}}{2}+(\gamma) \frac{Z_{2}^{2}+Z_{2}^{3}}{2} \\
& \operatorname{EV}_{\gamma}\left(\widetilde{Z}_{3}\right)=(1-\gamma) \frac{Z_{3}^{1}+Z_{3}^{2}}{2}+(\gamma) \frac{Z_{3}^{2}+Z_{3}^{3}}{2}
\end{aligned}
$$

Parameter $\gamma$ defines the degree of a decision maker's optimism and can be varied between zero and one [27]. This study takes a value of 0.3 for parameter $\gamma$.

(b) Treating Imprecise Constraints. This section addresses the issue of feasibility of solution. Here, based on the ranking approach of Jiménez et al. [37] as presented in (31), all imprecise (fuzzy) constraints of the model are converted to their equivalent crisp ones as follows:

$$
\begin{aligned}
& \sum_{h=1}^{2} P_{m h t} \geq\left(\frac{\alpha}{2}\right) \frac{D_{m t}^{2}+D_{m t}^{3}}{2}+\left(1-\frac{\alpha}{2}\right) \frac{D_{m t}^{1}+D_{m t}^{2}}{2}-I_{m(t-1)} \\
& -B_{m t}+I_{m t}+B_{m(t-1)} ; \quad \forall m, \forall t>1 \\
& \sum_{h=1}^{2} P_{m h t} \leq\left(1-\frac{\alpha}{2}\right) \frac{D_{m t}^{2}+D_{m t}^{3}}{2}+\left(\frac{\alpha}{2}\right) \frac{D_{m t}^{1}+D_{m t}^{2}}{2}-I_{m(t-1)} \\
& -B_{m t}+I_{m t}+B_{m(t-1)} ; \quad \forall m, \forall t>1 \\
& \sum_{h=1}^{2} P_{m h t} \geq\left(\frac{\alpha}{2}\right) \frac{D_{m t}^{2}+D_{m t}^{3}}{2}+\left(1-\frac{\alpha}{2}\right) \frac{D_{m t}^{1}+D_{m t}^{2}}{2} \\
& -B_{m t}+I_{m t} ; \quad \forall m, \quad t=1 \\
& \sum_{h=1}^{2} P_{m h t} \leq\left(1-\frac{\alpha}{2}\right) \frac{D_{m t}^{2}+D_{m t}^{3}}{2}+\left(\frac{\alpha}{2}\right) \frac{D_{m t}^{1}+D_{m t}^{2}}{2} \\
& -B_{m t}+I_{m t} ; \quad \forall m, \quad t=1 \\
& P_{m h t} \tau_{m} \leq \operatorname{Max}^{h t} \times\left[(1-\alpha) \frac{P A_{m}^{2}+P A_{m}^{3}}{2}\right. \\
& \left.+\alpha \frac{P A_{m}^{1}+P A_{m}^{2}}{2}\right] ; \quad \forall m, \forall t, \forall h \\
& B_{m t} \leq(1-\alpha) \frac{D_{m t}^{2}+D_{m t}^{3}}{2}+\alpha \frac{D_{m t}^{1}+D_{m t}^{2}}{2} ; \quad \forall m, \forall t .
\end{aligned}
$$

$\alpha$ is the feasibility degree [37] of the constraints that has been assigned by the decision maker based on the risk that he/she accepts about the violation of constraints imposed by the obtained solution [44]. In this study, a value of 0.8 has been considered for the parameter $\alpha$.

4.2.3. Solving the Resulting Multiobjective Crisp Linear Programming Model. Passing through stages 1 and 2, as shown in the previous sections, a multiobjective crisp model is obtained as follows:

$$
\begin{aligned}
& \operatorname{Min}\left(\operatorname{EV}_{\gamma}\left(\widetilde{Z}_{1}\right)=(1-\gamma) \frac{Z_{1}^{1}+Z_{1}^{2}}{2}+(\gamma) \frac{Z_{1}^{2}+Z_{1}^{3}}{2}\right) \\
& \operatorname{Min}\left(\operatorname{EV}_{\gamma}\left(\widetilde{Z}_{2}\right)=(1-\gamma) \frac{Z_{2}^{1}+Z_{2}^{2}}{2}+(\gamma) \frac{Z_{2}^{2}+Z_{2}^{3}}{2}\right) \\
& \operatorname{Max}\left(\operatorname{EV}_{\gamma}\left(\widetilde{Z}_{3}\right)=(1-\gamma) \frac{Z_{3}^{1}+Z_{3}^{2}}{2}+(\gamma) \frac{Z_{3}^{2}+Z_{3}^{3}}{2}\right)
\end{aligned}
$$

Subject to: Equations (8) - (10);

Equations (13)-(16);

Equation (37). 
TABLE 1: A typical payoff table for identification of positive and negative ideal solutions.

\begin{tabular}{lccc}
\hline & $v_{1}^{*}$ & $v_{2}^{*}$ & $v_{3}^{*}$ \\
\hline$Z_{1}$ & $Z_{1}\left(v_{1}^{*}\right)$ & $Z_{1}\left(v_{2}^{*}\right)$ & $Z_{1}\left(v_{3}^{*}\right)$ \\
$Z_{2}$ & $Z_{2}\left(v_{1}^{*}\right)$ & $Z_{2}\left(v_{2}^{*}\right)$ & $Z_{2}\left(v_{3}^{*}\right)$ \\
$Z_{3}$ & $Z_{3}\left(v_{1}^{*}\right)$ & $Z_{3}\left(v_{2}^{*}\right)$ & $Z_{3}\left(v_{3}^{*}\right)$ \\
\hline
\end{tabular}

TABle 2: Payoff table for obtaining positive and negative ideal solutions for the case study.

\begin{tabular}{lccc}
\hline & $v_{1}^{*}$ & $v_{2}^{*}$ & $v_{3}^{*}$ \\
\hline $\mathrm{EV}_{0.3}\left(\widetilde{Z}_{1}(x)\right)$ & 6171886216 & 11746702890 & 6217647286 \\
$\mathrm{EV}_{0.3}\left(\widetilde{Z}_{2}(x)\right)$ & 6.349 & 0.192 & 4.873 \\
$\mathrm{EV}_{0.3}\left(\widetilde{Z}_{3}(x)\right)$ & 5.826 & 4.402 & 5.826 \\
\hline
\end{tabular}

TABLE 3: Obtained positive and negative ideal solutions.

\begin{tabular}{lcc}
\hline & PIS & NIS \\
\hline $\operatorname{EV}_{0.3}\left(\widetilde{Z}_{1}(x)\right)$ & 6171886216 & 11746702890 \\
$\operatorname{EV}_{0.3}\left(\widetilde{Z}_{2}(x)\right)$ & 0.192 & 6.349 \\
$\operatorname{EV}_{0.3}\left(\widetilde{Z}_{3}(x)\right)$ & 5.826 & 4.402 \\
\hline
\end{tabular}

To solve the resulting multiobjective model, the fuzzy goal programming approach has been applied. This approach involves three different steps including identifying goal values for the defined objective functions, constructing a membership function for each of the objective functions based on the defined goal values, and lastly transforming multiple objectives to a single one by applying an aggregation operator. Consider an objective function $Z_{i}$ (minimization objective); the corresponding membership function is presented in Figure 3.

$Z_{i}^{\mathrm{PIS}}$ and $Z_{i}^{\mathrm{NIS}}$ are positive and negative ideal solutions of objective function $Z_{i}$, respectively. To determine the values of these two parameters, the approach used by Abd El-Wahed and Lee [47] has been followed in this study. Based on their approach, the maximum aspiration level $Z_{i}^{\text {PIS }}$ is obtained by solving the model based on a single objective of $Z_{i}$ and ignoring other objective functions. However, for obtaining the negative ideal solution of an objective function, one of the following equations should be applied:

$$
Z_{i}^{\mathrm{NIS}}=\max \left\{Z_{i}\left(v_{j}^{*}\right) ; i \neq j\right\}
$$

in case of having a minimization objective

$$
Z_{i}^{\mathrm{NIS}}=\min \left\{Z_{i}\left(v_{j}^{*}\right) ; i \neq j\right\}
$$

in case of having a maximization objective,

in which $v_{j}^{*}$ is the positive ideal solution of objective function $Z_{j}$. A typical payoff table is shown in Table 1.

Once all the membership functions are constructed, the fuzzy goal programming model can be formulated. Here, as

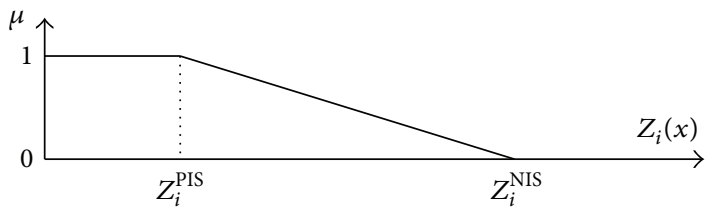

FIGURE 3: A typical membership function for a minimization objective.

the final step, the aim is to formulate an equivalent optimization model taking into account the goal values of all objective functions as well as the feasibility degree of constraints. To do so, the max-min operator of Bellman and Zadeh [48] was selected in order to convert the multiobjective linear model to an ordinary single objective linear programming model. By applying the max-min operator, the final model is derived as follows:

$$
\begin{array}{ll}
\operatorname{Max} & \varphi \\
\text { Subject to: } & \varphi \leq \mu_{\mathrm{EV}_{\gamma}\left(\widetilde{Z}_{i}(x)\right)} ; \quad i=1,2,3 \\
& \text { Equations }(8)-(10) ; \\
& \text { Equations }(13)-(16) ; \\
& \text { Equation }(37) ; \\
& 0 \leq \varphi \leq 1 ; \quad x \geq 0 .
\end{array}
$$

It is notable that the values of $\alpha$ and $\gamma$ are assigned by the decision maker. In some cases when an unsatisfactory result is obtained, she/he can change them until a satisfactory result is achieved.

\section{Applying the Proposed Model to the Company under Study}

Using the IBM ILOG CPLEX Optimization Studio (version 12.4) software and applying the data gathered from the company under study as well as the approach described earlier, a payoff table for identifying positive and negative ideal solutions of each objective function was constructed as shown in Table 2.

Therefore, the positive and negative ideal solutions are obtained as shown in Table 3.

Applying the obtained PISs and NISs and referring to Figure 3, the membership functions can be constructed as depicted in Figures 4, 5, and 6 and formulated in 


$$
\begin{aligned}
& \mu_{\mathrm{EV}_{0.3}\left(\widetilde{Z}_{1}(x)\right)}= \begin{cases}1 & \mathrm{EV}_{0.3}\left(\widetilde{Z}_{1}(x)\right) \leq 6171886216 \\
\frac{11746702890-\mathrm{EV}_{0.3}\left(\widetilde{Z}_{1}(x)\right)}{11746702890-6171886216} & 6171886216<\mathrm{EV}_{0.3}\left(\widetilde{Z}_{1}(x)\right) \leq 11746702890 \\
0 & \operatorname{EV}_{0.3}\left(\widetilde{Z}_{1}(x)\right)>11746702890\end{cases} \\
& \mu_{\mathrm{EV}_{0.3}\left(\widetilde{Z}_{2}(x)\right)}= \begin{cases}1 & \mathrm{EV}_{0.3}\left(\widetilde{Z}_{2}(x)\right) \leq 0.192 \\
\frac{6.349-\mathrm{EV}_{0.3}\left(\widetilde{Z}_{2}(x)\right)}{6.349-0.192} & 0.192<\mathrm{EV}_{0.3}\left(\widetilde{Z}_{2}(x)\right) \leq 6.349 \\
0 & \operatorname{EV}_{0.3}\left(\widetilde{Z}_{2}(x)\right)>6.349\end{cases} \\
& \mu_{\mathrm{EV}_{0.3}\left(\widetilde{Z}_{3}(x)\right)}= \begin{cases}0 & \mathrm{EV}_{0.3}\left(\widetilde{Z}_{3}(x)\right) \leq 4.402 \\
\frac{\mathrm{EV}_{0.3}\left(\widetilde{Z}_{3}(x)\right)-4.402}{5.826-4.402} & 4.402<\mathrm{EV}_{0.3}\left(\widetilde{Z}_{3}(x)\right) \leq 5.826 \\
1 & \operatorname{EV}_{0.3}\left(\widetilde{Z}_{3}(x)\right)>5.826 .\end{cases}
\end{aligned}
$$

As the final step for solving the constructed fuzzy goal programming model, the max-min operator of Bellman and Zadeh [48] was applied as an aggregation operator to convert the multiobjective linear model to an equivalent single objective one. Therefore, the final model is shown as follows:

$$
\begin{array}{ll}
\text { Max } & \varphi \\
\text { Subject to: } & \varphi \leq \mu_{\mathrm{EV}_{0.3}\left(\widetilde{Z}_{1}(x)\right)} \\
& \varphi \leq \mu_{\mathrm{EV}_{0.3}\left(\widetilde{Z}_{2}(x)\right)} \\
& \varphi \leq \mu_{\mathrm{EV}_{0.3}\left(\widetilde{Z}_{3}(x)\right)} \\
& \mu_{\mathrm{EV}_{0.3}\left(\widetilde{Z}_{1}(x)\right)}=\frac{11746702890-\mathrm{EV}_{0.3}\left(\widetilde{Z}_{1}(x)\right)}{11746702890-6171886216} \\
& \mu_{\mathrm{EV}_{0.3}\left(\widetilde{Z}_{2}(x)\right)}=\frac{6.349-\mathrm{EV}_{0.3}\left(\widetilde{Z}_{2}(x)\right)}{6.349-0.192} \\
& \mu_{\mathrm{EV}_{0.3}\left(\widetilde{Z}_{3}(x)\right)}=\frac{\mathrm{EV}_{0.3}\left(\widetilde{Z}_{3}(x)\right)-4.402}{5.826-4.402} \\
& \operatorname{EV}_{0.3}\left(\widetilde{Z}_{1}\right)=(1-0.3) \frac{Z_{1}^{1}+Z_{1}^{2}}{2}+(0.3) \frac{Z_{1}^{2}+Z_{1}^{3}}{2} \\
& \operatorname{EV}_{0.3}\left(\widetilde{Z}_{2}\right)=(1-0.3) \frac{Z_{2}^{1}+Z_{2}^{2}}{2}+(0.3) \frac{Z_{2}^{2}+Z_{2}^{3}}{2} \\
& \operatorname{EV}_{0.3}\left(\widetilde{Z}_{3}\right)=(1-0.3) \frac{Z_{3}^{1}+Z_{3}^{2}}{2}+(0.3) \frac{Z_{3}^{2}+Z_{3}^{3}}{2}
\end{array}
$$

Equations (8) - (10);

Equations (13)-(16);

$$
\begin{aligned}
& \text { Equation (37); } \\
& 0 \leq \varphi \leq 1 ; \quad x \geq 0,
\end{aligned}
$$

where $\alpha=0.8$ is substituted in (37).

\section{Discussion of Results}

Using the aforementioned software, the detailed solutions to the above model were obtained as presented in Tables 4, 5, and 6. As stated earlier, the values for parameters $\alpha$ and $\gamma$ have been considered as 0.8 and 0.3 , respectively.

Table 4 contains the optimal values obtained for each of the objective functions. As can be seen, the obtained optimal values of objective functions are relatively close to the aspiration levels that have been defined in (41) and presented in Figures 4 to 6 . Table 5 presents the results obtained for some decision variables, including inventory and backorder levels, production quantities, and number of workers to be trained in different time periods. Investigating these results shows that incurring inventory and having overtime production are more preferred than having backorders in many time periods. The reason can be attributed to the higher penalty cost of backorders compared to the cost of carrying inventory or/and having overtime production in the company under study. In addition, considering the third objective function that aims to increase customer service level by reducing backorder levels has its own effect on obtaining such results.

Based on the results obtained for the number of workers to be trained (the last column of Table 5) and the results shown in Table 6 which suggest the number of workers with certain level of skill to be hired at the beginning of each time period, it is concluded that hiring workers with the required skill levels and avoiding training cost is more beneficial for the company under study.

Results related to purchasing raw materials $Q_{i k t}$ which are not shown because of space limitation determine the 


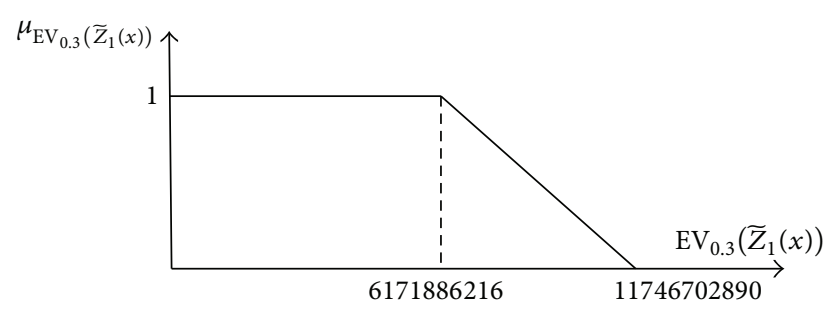

FIgURE 4: Membership function for the first objective.

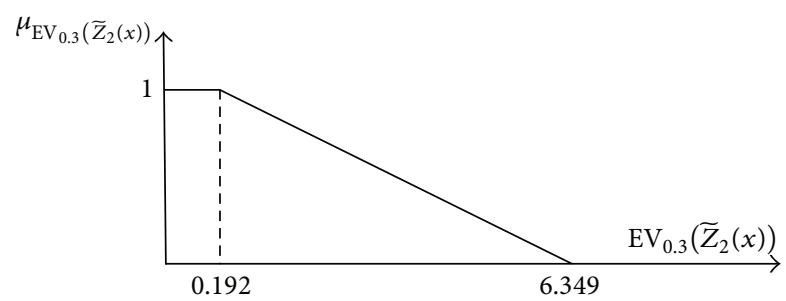

Figure 5: Membership function for the second objective.

TABLE 4: Results obtained for objective functions and $\varphi$.

\begin{tabular}{lc}
\hline 1st objective & 6277251051 \\
\hline 2nd objective & 0.31 \\
\hline 3rd objective & 5.83 \\
\hline$\varphi$ & 0.98 \\
\hline
\end{tabular}

quantity of different types of raw materials to be purchased from different suppliers in various time periods, taking into account two important elements, that are, cost of purchasing and lower reject rate of purchased components as a measure of quality.

As one of the contributions of this research is to signify the importance of considering the performance and availability levels of production lines in developing an APP, a comparison was performed between the results obtained with and without considering these two parameters in the model.

Figures 7, 8, and 9 present a comparison between the results obtained for the three objective functions, that are, minimization of cost, maximization of quality (minimization of quality degradation), and maximization of customer service level, with and without considering the performance and availability of production lines. In addition, Figures 10 to 12 provide the same comparison between the results obtained for some decision variables including production quantity (in regular time and overtime), inventory level, and backorder level, respectively. The differences between the results obtained illustrate the role of the two factors (performance and availability levels) in developing a practical and real APP. Failure to take into account these two parameters can lead planners to inaccurate results which are completely different from the actual results obtained in their presence. The differences between the outputs in the two considered situations are due to the overestimation of production capacity stemming from ignoring the level of performance and

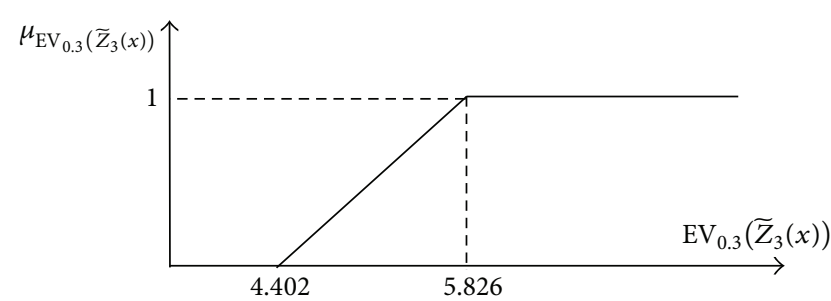

FIgURE 6: Membership function for the third objective.

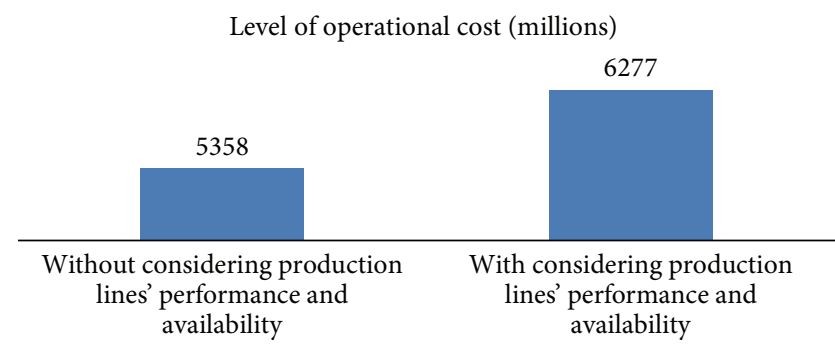

Figure 7: Comparison between the results obtained for the first objective function.

availability of production lines. In other words, unrealistic assumption about the capacity of production lines results in ineffective production planning. For example, the quantity of products that can be generated during regular time has been overestimated and the required quantity to be produced during overtime has been underestimated (Figure 10). Figures 11 and 12 also show the underestimation of inventory and backorder levels, respectively. The overestimation of production quantity in regular time is due to the overestimation of production capacity that allows generating more products in regular time in order to lower the production quantity in overtime and consequently the associated cost. The higher levels of total inventory and backorder, when considering the performance and availability parameters, can be associated with the lack of capacity for producing the required number of products in the corresponding time periods. Therefore, the company should compensate for the shortage by incurring higher inventory and carrying more backorder levels. Underestimating backorder and inventory levels can have at least two consequences. The first one results in underestimation of operational cost due to underestimation of backorder and inventory levels as the two main portions of the total operational cost (Figure 7) and the second consequence manifests itself in producing behind schedule and having inaccurate backorder levels which ultimately leads to customer dissatisfaction and sales loss. Therefore, in order to avoid developing an impractical APP with unrealistic estimation of resources on hand, it is necessary to take into account performance and availability factors when developing a practical APP. 
TABLE 5: Results corresponding to inventory and backorder levels, production quantity, and number of workers to train.

\begin{tabular}{|c|c|c|c|c|c|c|}
\hline Product & Time period & Inventory level & Backorder level & $\begin{array}{l}\text { Regular time } \\
\text { production } \\
\text { quantity }\end{array}$ & $\begin{array}{l}\text { Overtime } \\
\text { production } \\
\text { quantity }\end{array}$ & $\begin{array}{c}\text { Number of } \\
\text { workers to train }\end{array}$ \\
\hline 1 & 1 & 9031 & 0 & 8445 & 5278 & 0 \\
\hline 1 & 2 & 4538 & 0 & 8445 & 5278 & 0 \\
\hline 1 & 3 & 3081 & 0 & 8445 & 5278 & 0 \\
\hline 1 & 4 & 0 & 6587 & 8445 & 5278 & 0 \\
\hline 1 & 5 & 0 & 9424 & 8445 & 5278 & 0 \\
\hline 1 & 6 & 0 & 0 & 7082 & 5278 & 0 \\
\hline 2 & 1 & 3265 & 0 & 0 & 4579 & 0 \\
\hline 2 & 2 & 7312 & 0 & 4800 & 4579 & 0 \\
\hline 2 & 3 & 5018 & 0 & 0 & 0 & 0 \\
\hline 2 & 4 & 0 & 0 & 0 & 0 & 0 \\
\hline 2 & 5 & 2837 & 0 & 7326 & 0 & 0 \\
\hline 2 & 6 & 0 & 0 & 0 & 3517 & 0 \\
\hline 3 & 1 & 7981 & 0 & 7420 & 10929 & 0 \\
\hline 3 & 2 & 19260 & 0 & 17487 & 10929 & 0 \\
\hline 3 & 3 & 8679 & 0 & 17487 & 10929 & 0 \\
\hline 3 & 4 & 20205 & 0 & 17487 & 10929 & 0 \\
\hline 3 & 5 & 18433 & 0 & 17487 & 10929 & 0 \\
\hline 3 & 6 & 0 & 0 & 17487 & 10929 & 0 \\
\hline
\end{tabular}

TABLE 6: Number of workers with the required skill levels in different time periods.

\begin{tabular}{|c|c|c|c|c|c|c|c|c|c|c|c|}
\hline Product & $\begin{array}{l}\text { Skill } \\
\text { level }\end{array}$ & $\begin{array}{c}\text { Time } \\
\text { period }\end{array}$ & $\begin{array}{c}\text { Number of } \\
\text { workers }\end{array}$ & Product & $\begin{array}{l}\text { Skill } \\
\text { level }\end{array}$ & $\begin{array}{c}\text { Time } \\
\text { period }\end{array}$ & $\begin{array}{c}\text { Number of } \\
\text { workers }\end{array}$ & Product & $\begin{array}{l}\text { Skill } \\
\text { level }\end{array}$ & $\begin{array}{c}\text { Time } \\
\text { period }\end{array}$ & $\begin{array}{c}\text { Number of } \\
\text { workers }\end{array}$ \\
\hline 1 & 1 & 1 & 0 & 2 & 1 & 1 & 0 & 3 & 1 & 1 & 0 \\
\hline 1 & 1 & 2 & 0 & 2 & 1 & 2 & 0 & 3 & 1 & 2 & 0 \\
\hline 1 & 1 & 3 & 0 & 2 & 1 & 3 & 0 & 3 & 1 & 3 & 0 \\
\hline 1 & 1 & 4 & 0 & 2 & 1 & 4 & 0 & 3 & 1 & 4 & 0 \\
\hline 1 & 1 & 5 & 0 & 2 & 1 & 5 & 0 & 3 & 1 & 5 & 0 \\
\hline 1 & 1 & 6 & 0 & 2 & 1 & 6 & 0 & 3 & 1 & 6 & 0 \\
\hline 1 & 2 & 1 & 10 & 2 & 2 & 1 & 10 & 3 & 2 & 1 & 6 \\
\hline 1 & 2 & 2 & 10 & 2 & 2 & 2 & 10 & 3 & 2 & 2 & 6 \\
\hline 1 & 2 & 3 & 10 & 2 & 2 & 3 & 10 & 3 & 2 & 3 & 6 \\
\hline 1 & 2 & 4 & 10 & 2 & 2 & 4 & 10 & 3 & 2 & 4 & 6 \\
\hline 1 & 2 & 5 & 10 & 2 & 2 & 5 & 10 & 3 & 2 & 5 & 6 \\
\hline 1 & 2 & 6 & 10 & 2 & 2 & 6 & 10 & 3 & 2 & 6 & 6 \\
\hline 1 & 3 & 1 & 0 & 2 & 3 & 1 & 0 & 3 & 3 & 1 & 0 \\
\hline 1 & 3 & 2 & 0 & 2 & 3 & 2 & 0 & 3 & 3 & 2 & 0 \\
\hline 1 & 3 & 3 & 0 & 2 & 3 & 3 & 0 & 3 & 3 & 3 & 0 \\
\hline 1 & 3 & 4 & 0 & 2 & 3 & 4 & 0 & 3 & 3 & 4 & 0 \\
\hline 1 & 3 & 5 & 0 & 2 & 3 & 5 & 0 & 3 & 3 & 5 & 0 \\
\hline 1 & 3 & 6 & 0 & 2 & 3 & 6 & 0 & 3 & 3 & 6 & 0 \\
\hline
\end{tabular}

\section{Sensitivity Analysis}

Figures 13 to 15 provide information about sensitivity analysis, which was performed on parameters $\alpha$ and $\gamma$. As clarified earlier, these two parameters were arbitrarily set by the decision maker. In selecting these parameters, the decision maker ran into performing a trade-off between obtaining a better optimal value which is closer to the targeted aspiration level of the objective function (the set composed of those values whose membership functions are equal to one) and 


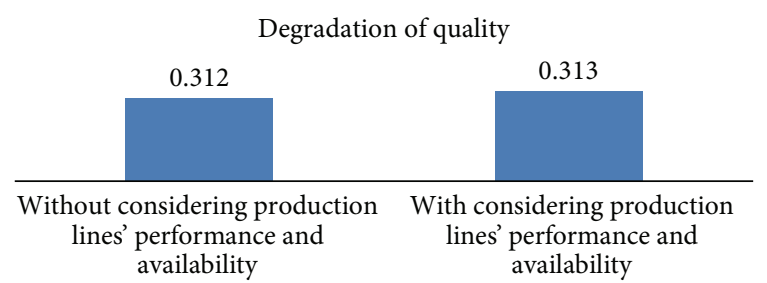

FIGURE 8: Comparison between the results obtained for the second objective function.

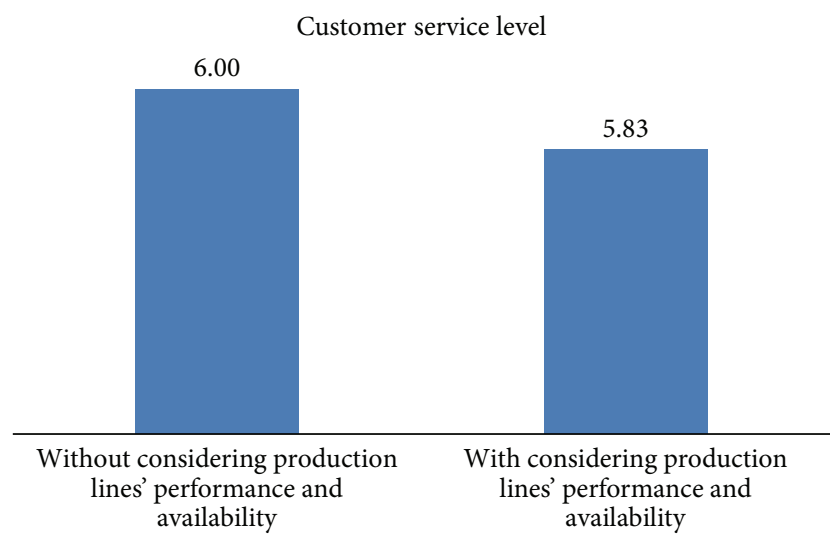

FIgURE 9: Comparison between the results obtained for the third objective function.

Total production quantity during the time horizon

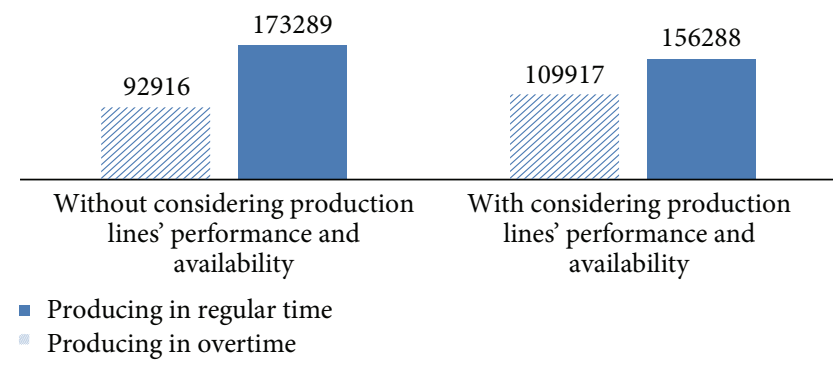

FIgUre 10: Comparison between total production quantities (assigned to all products) during the time horizon.

Total inventory level during the time horizon

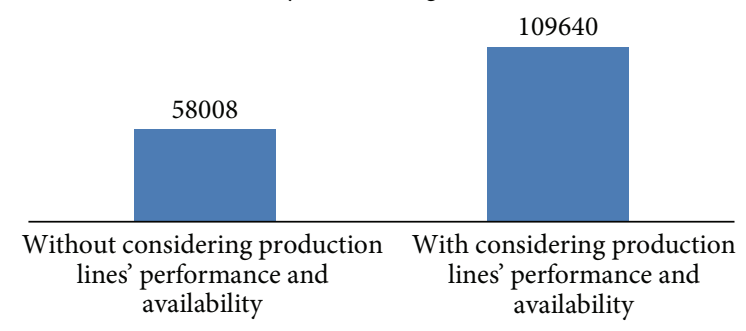

Figure 11: Comparison between total inventory levels (assigned to all products) during the time horizon.
Total backorder level during the time horizon

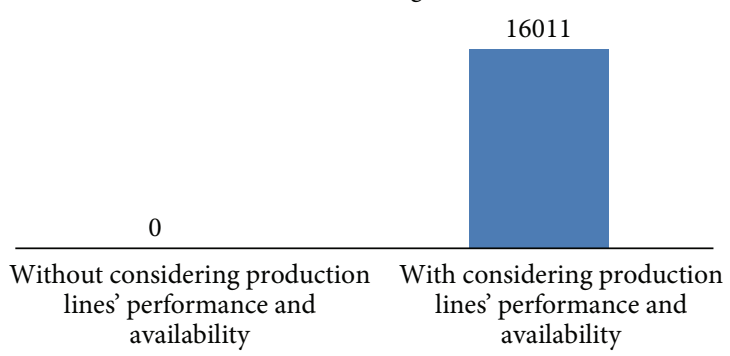

Figure 12: Comparison between total backorder levels (assigned to all products) during the time horizon.

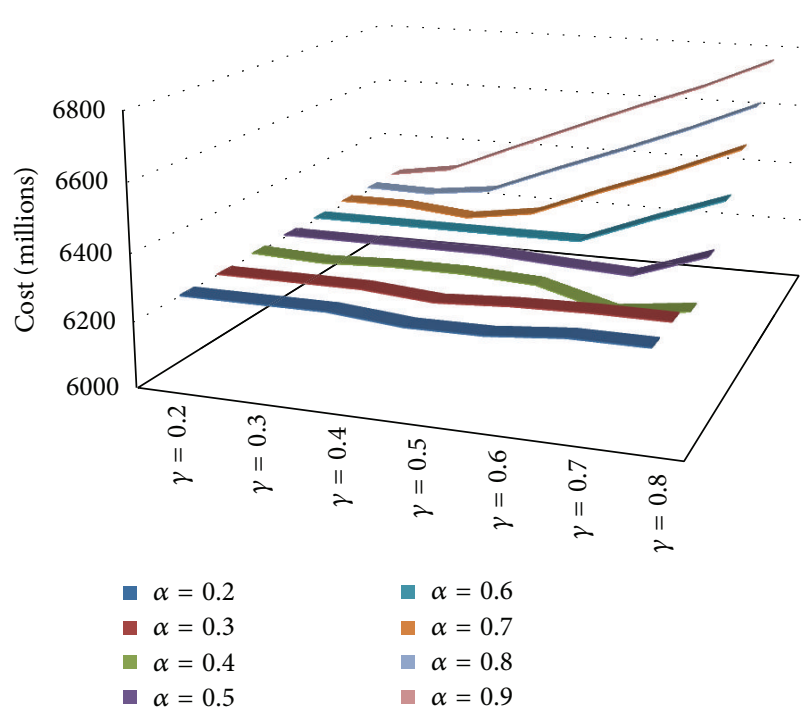

FIGURE 13: Sensitivity analysis on the first objective function.

having a higher degree of satisfaction of constraints, that is, selecting a higher feasibility degree. A general view of the results associated with the performed sensitivity analysis reflects the fact that a better optimal value of an objective function requires a lesser degree of feasibility (a higher risk of violating constraints) [37]. As can be generally observed from Figure 13, better optimal values for the first objective function, that are, values with higher membership degrees for the set $\{x \in R \mid 6171886216 \leq x \leq 11746702890\}$ (see Figure 4), are obtained at lesser degrees of feasibility (lesser values of parameter $\alpha$ ). For example, for a certain value of $\gamma$ in Figure 13, increasing the value of parameter $\alpha$ generally results in worsening the value of cost (higher cost) and obtaining optimal solutions with a lower membership degree for the set introduced above. Although the second and third objective functions (Figures 14 and 15, resp.) show relatively subtle sensitivity, the trends shown in these two figures do not reveal conflicts with the aforementioned fact.

\section{Conclusions}

In this paper, an attempt was made to propose an integer linear programming model for APP of an automotive parts 


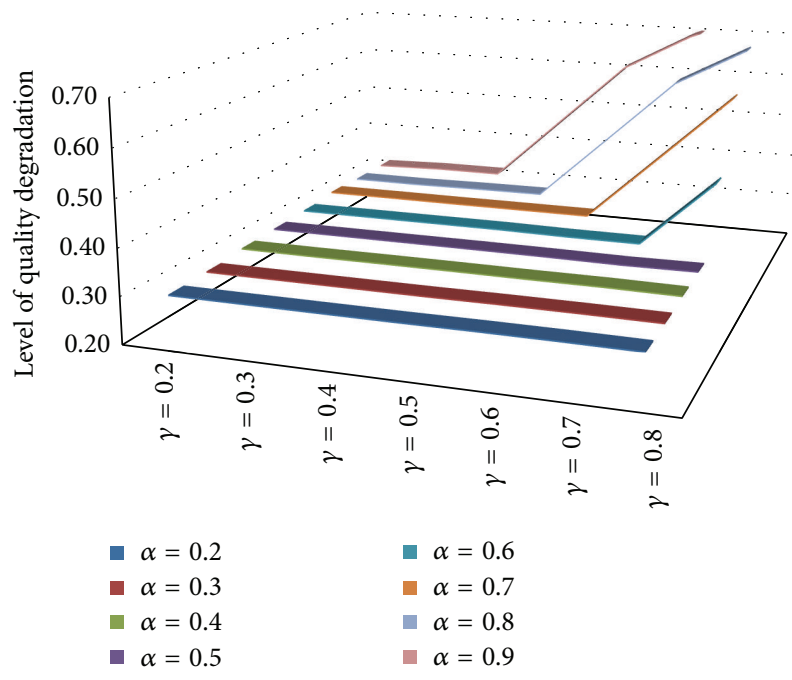

FIGURE 14: Sensitivity analysis on the second objective function.

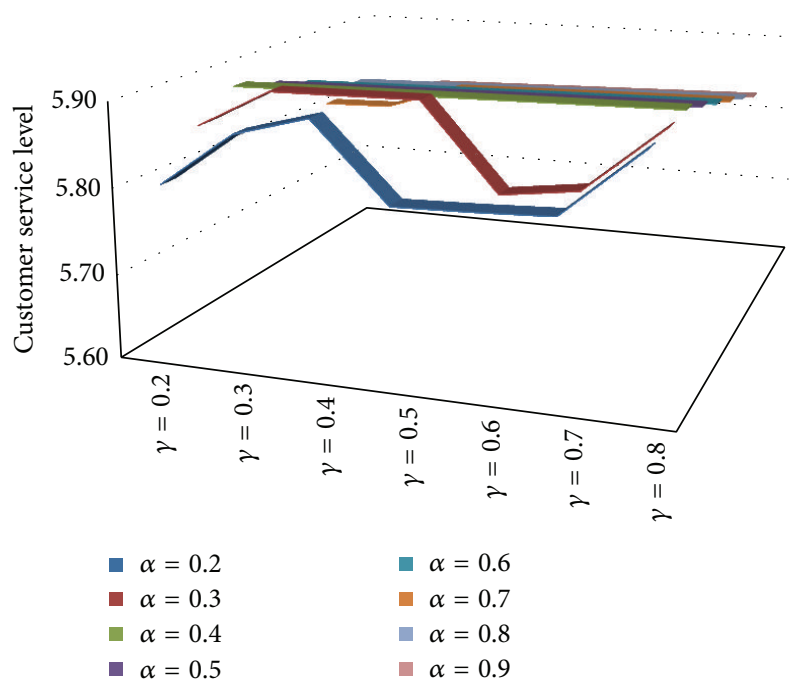

FIGURE 15: Sensitivity analysis on the third objective function.

manufacturing company in a fuzzy environment that takes into account quality of products as well as other common objectives used in the literature which are minimization of cost and maximization of customer service level. Since, in the real world, many planners have some qualitative objectives expressed in the form of linguistic terms, an effort was made to incorporate a qualitative objective function in the construction of the mathematical model. To make the plan more practical, it has taken into account the real capacity of production lines when formulating the model through the consideration of two important factors which are performance and availability of production lines. The model was solved using the IBM ILOG CPLEX software. To highlight the importance of considering the performance and availability of production lines, a comparison was made between the results obtained from solving the model with and without the consideration of these two factors. The comparison obviously showed that ignoring these two factors can result in generating an inaccurate plan which is not practical in reality.

\section{Conflict of Interests}

The authors declare that there is no conflict of interests regarding the publication of this paper.

\section{References}

[1] A. Jain and U. S. Palekar, "Aggregate production planning for a continuous reconfigurable manufacturing process," Computers and Operations Research, vol. 32, no. 5, pp. 1213-1236, 2005.

[2] R. C. Wang and T. F. Liang, "Application of fuzzy multi-objective linear programming to aggregate production planning," Computers and Industrial Engineering, vol. 46, no. 1, pp. 17-41, 2004.

[3] R. Zhang, L. Zhang, Y. Xiao, and I. Kaku, "The activitybased aggregate production planning with capacity expansion in manufacturing systems," Computers \& Industrial Engineering, vol. 62, no. 2, pp. 491-503, 2012.

[4] S. Chopra and P. Meindl, Supply Chain Management. Strategy, Planning, and Operation, Gabler, 2007.

[5] J. Tang, D. Wang, and R. Y. K. Fung, "Fuzzy formulation for multi-product aggregate production planning," Production Planning and Control, vol. 11, no. 7, pp. 670-676, 2000.

[6] C. Gomes da Silva, J. Figueira, J. Lisboa, and S. Barman, "An interactive decision support system for an aggregate production planning model based on multiple criteria mixed integer linear programming," Omega, vol. 34, no. 2, pp. 167-177, 2006.

[7] R. Ramezanian, D. Rahmani, and F. Barzinpour, "An aggregate production planning model for two phase production systems: solving with genetic algorithm and tabu search," Expert Systems with Applications, vol. 39, no. 1, pp. 1256-1263, 2012.

[8] A. P. Kanyalkar and G. K. Adil, "An integrated aggregate and detailed planning in a multi-site production environment using linear programming," International Journal of Production Research, vol. 43, no. 20, pp. 4431-4454, 2005.

[9] V. Jayaraman, "Production planning for closed-loop supply chains with product recovery and reuse: an analytical approach," International Journal of Production Research, vol. 44, no. 5, pp. 981-998, 2006.

[10] T. Sillekens, A. Koberstein, and L. Suhl, "Aggregate production planning in the automotive industry with special consideration of workforce flexibility," International Journal of Production Research, vol. 49, no. 17, pp. 5055-5078, 2011.

[11] I. T. Christou, A. G. Lagodimos, and D. Lycopoulou, "Hierarchical production planning for multi-product lines in the beverage industry," Production Planning and Control, vol. 18, no. 5, pp. 367-376, 2007.

[12] C. G. Vassiliadis, M. G. Vassiliadou, L. G. Papageorgiou, and E. N. Pistikopoulos, "Simultaneous maintenance considerations and production planning in multi-purpose plants," in Proceedings of the Annual Reliability and Maintainability Symposium, pp. 228-233, IEEE, 2000.

[13] H. Suryadi and L. G. Papageorgiou, "Optimal maintenance planning and crew allocation for multipurpose batch plants," International Journal of Production Research, vol. 42, no. 2, pp. 355-377, 2004

[14] A. K. Rifai, "A note on the structure of the goal-programming model: assessment and evaluation," International Journal of 
Operations \& Production Management, vol. 16, no. 1, pp. 40-49, 1996.

[15] S. C. H. Leung and S. S. W. Chan, "A goal programming model for aggregate production planning with resource utilization constraint," Computers and Industrial Engineering, vol. 56, no. 3, pp. 1053-1064, 2009.

[16] C. Romero, "A general structure of achievement function for a goal programming model," European Journal of Operational Research, vol. 153, no. 3, pp. 675-686, 2004.

[17] A. Baykasoglu, "MOAPPS 1.0: aggregate production planning using the multiple-objective tabu search," International Journal of Production Research, vol. 39, no. 16, pp. 3685-3702, 2001.

[18] Z. H. Che and C. J. Chiang, "A modified Pareto genetic algorithm for multi-objective build-to-order supply chain planning with product assembly," Advances in Engineering Software, vol. 41, no. 7-8, pp. 1011-1022, 2010.

[19] Z. Liu, D. K. H. Chua, and K. Yeoh, "Aggregate production planning for shipbuilding with variation-inventory trade-offs," International Journal of Production Research, vol. 49, no. 20, pp. 6249-6272, 2011.

[20] A. S. M. Masud and C. L. Hwang, "An aggregate production planning model and application of three multiple objective decision methods," International Journal of Production Research, vol. 18, no. 6, pp. 741-752, 1980.

[21] H. S. Yan, Q. Xia, M. Zhu, X. Liu, and Z. Guo, "Integrated production planning and scheduling on automobile assembly lines," IIE Transactions, vol. 35, no. 8, pp. 711-725, 2003.

[22] L. Pradenas, F. Peñailillo, and J. Ferland, "Aggregate production planning problem. A new algorithm," Electronic Notes in Discrete Mathematics, vol. 18, pp. 193-199, 2004.

[23] A. Jamalnia and M. A. Soukhakian, "A hybrid fuzzy goal programming approach with different goal priorities to aggregate production planning," Computers and Industrial Engineering, vol. 56, no. 4, pp. 1474-1486, 2009.

[24] S. M. J. Mirzapour Al-E-Hashem, H. Malekly, and M. B. Aryanezhad, "A multi-objective robust optimization model for multi-product multi-site aggregate production planning in a supply chain under uncertainty," International Journal of Production Economics, vol. 134, no. 1, pp. 28-42, 2011.

[25] H. J. Zimmermann, "Description and optimization of fuzzy systems," International Journal of General Systems, vol. 2, no. 4, pp. 209-215, 1976.

[26] H. J. Zimmermann, "Fuzzy programming and linear programming with several objective functions," Fuzzy Sets and Systems, vol. 1, no. 1, pp. 45-55, 1978.

[27] R. G. Yaghin, S. A. Torabi, and S. M. T. F. Ghomi, "Integrated markdown pricing and aggregate production planning in a two echelon supply chain: a hybrid fuzzy multiple objective approach," Applied Mathematical Modelling, vol. 36, no. 12, pp. 6011-6030, 2012.

[28] R. Narasimhan, "Goal programming in a fuzzy environment," Decision Sciences, vol. 11, no. 2, pp. 325-336, 1980.

[29] E. L. Hannan, "Linear programming with multiple fuzzy goals," Fuzzy Sets and Systems, vol. 6, no. 3, pp. 235-248, 1981.

[30] B. K. Wong and V. S. Lai, "A survey of the application of fuzzy set theory in production and operations management: 1998-2009," International Journal of Production Economics, vol. 129, no. 1, pp. 157-168, 2011.

[31] D. B. Rinks, "The performance of fuzzy algorithm models for aggregate planning under differing cost structures," in Fuzzy Information and Decision Processes, M. M. Gupta and E.
Sanchez, Eds., pp. 267-278, North-Holland, Amsterdam, The Netherlands, 1982.

[32] Y. Y. Lee, Fuzzy Sets Theory Approach to Aggregate Production Planning and Inventory Control, UMI, 1990.

[33] M. Gen, Y. Tsujimura, and K. Ida, "Method for solving multiobjective aggregate production planning problem with fuzzy parameters," Computers \& Industrial Engineering, vol. 23, no. 14, pp. 117-120, 1992.

[34] R. Wang and H. Fang, "Aggregate production planning with multiple objectives in a fuzzy environment," European Journal of Operational Research, vol. 133, no. 3, pp. 521-536, 2001.

[35] R. Wang and T. Liang, "Application of fuzzy multi-objective linear programming to aggregate production planning," Computers and Industrial Engineering, vol. 46, no. 1, pp. 17-41, 2004.

[36] L. A. Zadeh, “Fuzzy sets," Information and Computation, vol. 8, pp. 338-353, 1965.

[37] M. Jiménez, M. Arenas, A. Bilbao, and M. V. Rodríguez, "Linear programming with fuzzy parameters: an interactive method resolution," European Journal of Operational Research, vol. 177, no. 3, pp. 1599-1609, 2007.

[38] Y. Lai and C. Hwang, "A new approach to some possibilistic linear programming problems," Fuzzy Sets and Systems, vol. 49, no. 2, pp. 121-133, 1992.

[39] M. S. Pishvaee and S. A. Torabi, "A possibilistic programming approach for closed-loop supply chain network design under uncertainty," Fuzzy Sets and Systems, vol. 161, no. 20, pp. 26682683, 2010.

[40] R. R. Yager, "A procedure for ordering fuzzy subsets of the unit interval," Information Sciences, vol. 24, no. 2, pp. 143-161, 1981.

[41] D. Dubois and H. Prade, "The mean value of a fuzzy number," Fuzzy Sets and Systems, vol. 24, no. 3, pp. 279-300, 1987.

[42] S. Heilpern, “The expected value of a fuzzy number," Fuzzy Sets and Systems, vol. 47, no. 1, pp. 81-86, 1992.

[43] M. Jiménez, "Ranking fuzzy numbers through the comparison of its expected intervals," International Journal of Uncertainty, Fuzziness and Knowledge-Based Systems, vol. 4, no. 4, pp. 379388, 1996.

[44] M. M. Lotfi and S. A. Torabi, "A fuzzy goal programming approach for mid-term assortment planning in supermarkets," European Journal of Operational Research, vol. 213, no. 2, pp. 430-441, 2011.

[45] S. A. Torabi and E. Hassini, "An interactive possibilistic programming approach for multiple objective supply chain master planning," Fuzzy Sets and Systems, vol. 159, no. 2, pp. 193-214, 2008.

[46] T.-F. Liang, "Application of fuzzy sets to manufacturing/distribution planning decisions in supply chains," Information Sciences, vol. 181, no. 4, pp. 842-854, 2011.

[47] W. F. Abd El-Wahed and S. M. Lee, "Interactive fuzzy goal programming for multi-objective transportation problems," Omega, vol. 34, no. 2, pp. 158-166, 2006.

[48] R. E. Bellman and L. A. Zadeh, "Decision-making in a fuzzy environment,” Management Science, vol. 17, pp. 141-161, 1970. 


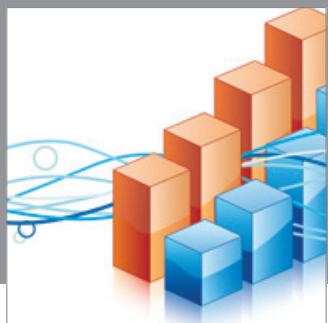

Advances in

Operations Research

mansans

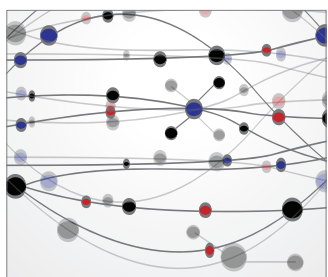

The Scientific World Journal
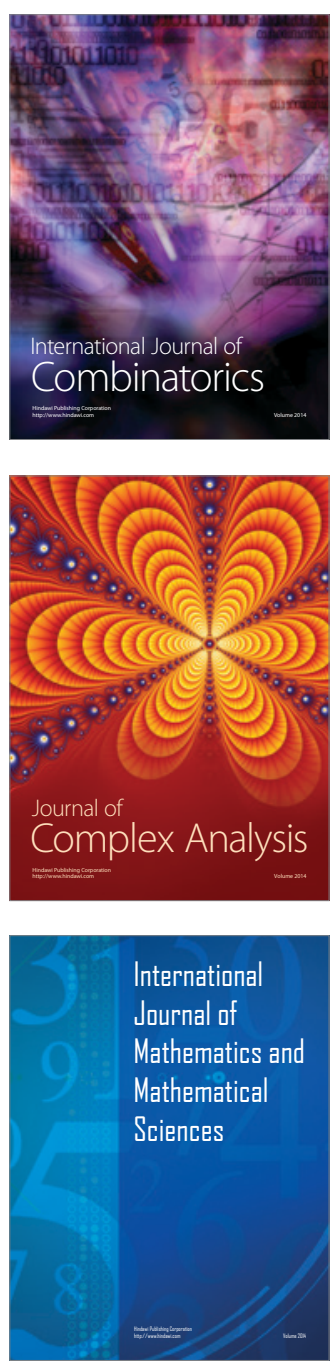
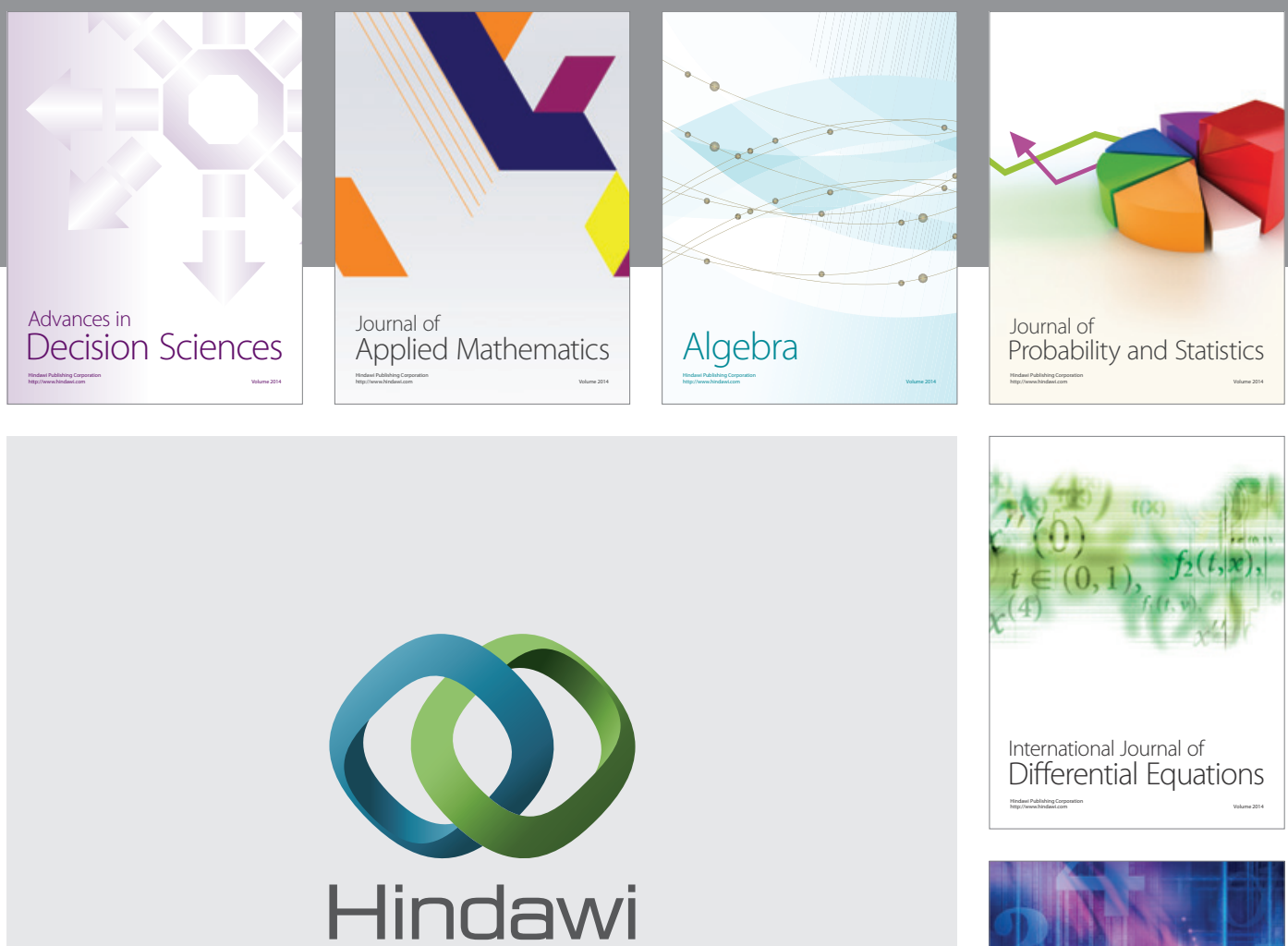

Submit your manuscripts at http://www.hindawi.com
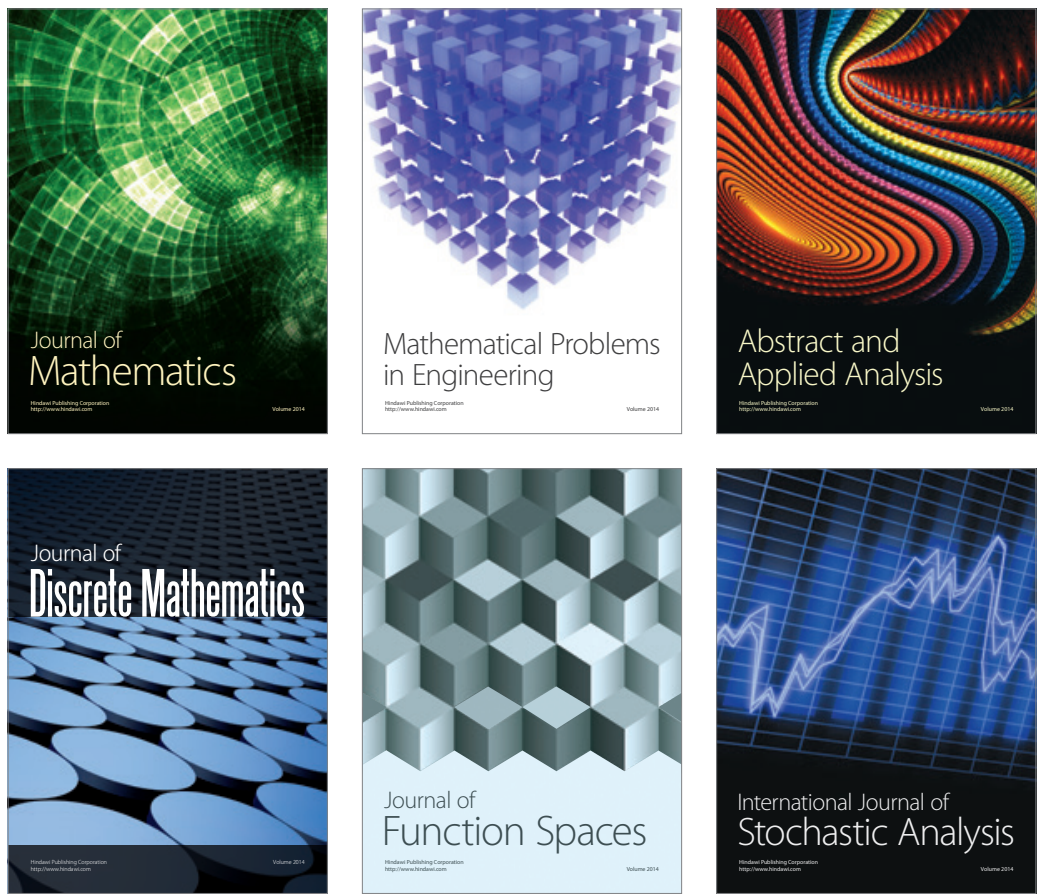

Journal of

Function Spaces

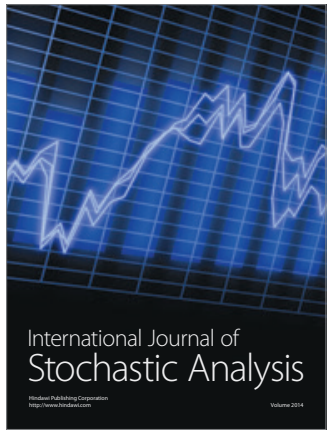

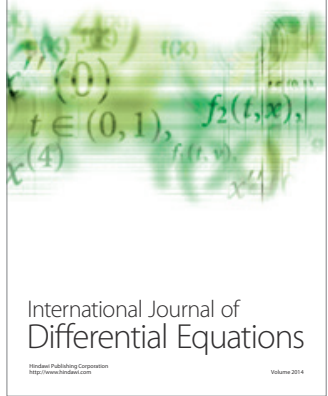
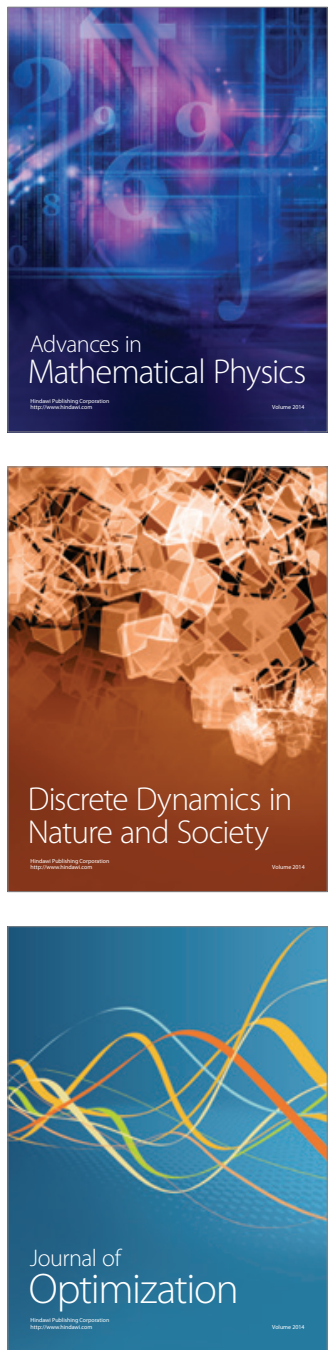